\title{
Ensuring representative economic data: survey data-collection methods in France for implementing the Common Fisheries Policy
}

Sylvie Van Iseghem*, Emmanuelle Quillérou, Cécile Brigaudeau, Claire Macher, Olivier Guyader and Fabienne Daurès

Ifremer, UMR AMURE, Unité d'Economie Maritime, Département Ressources Biologiques et Environnement, BP 70, F-29280 Plouzané Cedex, France

*: Corresponding author : Sylvie Van Iseghem, tel: +33298224925 ; fax: +33298224776 ; email address : svaniseg@ifremer.fr

\begin{abstract}
:
Since 2001, Ifremer has implemented an economic data collection programme (EDCP) within the Data Collection Framework of the EU. It aims to obtain economic data from a sample of vessels representative of the entire French fishing fleet. This paper presents the strategies used for vessel sampling selection in the French EDCP and its implementation over several consecutive years. The approach is illustrated by the sampling plan for the fleet in the North Sea Channel Atlantic region. We show that the EDCP allows precise economic indicators such as gross revenue or fuel costs to be estimated for the whole fishing fleet, including small vessels $(<10 \mathrm{~m})$, and consequently, it facilitates sound scientific advice regarding the Common Fisheries Policy. The apparent underestimation of landings by small vessels in official statistics is highlighted.
\end{abstract}

Keywords : data collection ; economic indicators ; fishery-dependent information ; panel data ; sampling ; small vessels ; statistical precision 


\section{Introduction}

In 1995, the Code of Conduct for Responsible Fisheries was adopted by the UN's Food and Agriculture Organization (FAO, 1995). It emphasized that the development of fisherymanagement plans required appropriate and reliable data on all aspects of a fishery. In particular, the Code stressed that "in order to ensure the sustainable management of fisheries and to enable social and economic objectives to be achieved, sufficient knowledge of social, economic and institutional factors should be developed through data gathering, analysis and research" (FAO, 1995, p. 12). Based on these considerations, the European Council (EC) of the European Union (EU) decided in 2000 to establish a Data Collection Framework (DCF; EC, 2008) to evaluate the situation of the fishing sector under the Common Fisheries Policy (CFP). The DCF specifies the type of data to be collected and the economic indicators to be computed. It also specifies the sample representativeness to be achieved within different fishing areas and fleet segments, defined as the combination of a particular fishing method and a vessel length category.

Today, the key role of economics in the development of fishery-management plans has become well established within European and international institutions as well as in the scientific community (Pascoe, 2006). Many studies have indeed shown the importance of economics in the ecosystem approach to fisheries, e.g. Garcia (2005) and Daurès et al. (2009). A good economic assessment of fisheries, however, depends on the quality, reliability, and completeness of the fishery-dependent data used. This consideration has been mostly neglected in the literature so far, with few studies explicitly assessing the quality of data (Chuenpagdee et al., 2006). Mettling et al. (1995) and Le Pape and Vigneau (2001) noted the underestimation in French official statistics of the landings by small vessels (here defined as being $<10 \mathrm{~m}$ long). As small vessels constitute $59 \%$ of the French fleet (excluding overseas fleets) in terms of number of vessels, and $25 \%$ of the total engine power, this underestimation is an important problem to be addressed.

This paper presents the two-stage methodology developed by Ifremer from 2001 for its economic data collection programme (EDCP) to guarantee the representativeness of sampling data across the whole fishing fleet. The EDCP economic database has, for instance, been used to estimate the economic dependence and species-landing profiles of French fleets in the Bay of Biscay (Daurès et al., 2009). It also plays a key role in the impact assessment of management measures (Macher et al., 2008) and other ongoing work in partnership with fishers and their representatives, government administrations, biologists, sociologists, and fishery economists. The first stage optimizes the sampling plan for a given year across fleet segments and distributes samples across maritime registration districts (MRDs). This sampling design is suitable whether the economic heterogeneity within a fleet segment is higher (e.g. small vessels) or lower (e.g. longer vessels). The second stage aims to reduce non-responses to questionnaires, through differential grouping of interviewees in MRDs. A network of permanent observers who collect data for various purposes, of which economic analysis is just one, also contributes to increase response (Leblond et al., 2008). Results are presented in terms of the quality of the survey design (bias and precision), following the recommendations of STECF (2009b), non-response rates, and economicindicator estimates such as gross revenue and fuel costs. We also provide evidence of the underestimation of small-vessel landings in official statistics, which has rarely been reported in the literature. 


\section{Fishing fleet and sampling strategies}

Ifremer collects economic data for French vessels $<40 \mathrm{~m}$ long operating in three supraregions defined in the DCF regulation: (i) the North Sea Channel Atlantic (NSCA), i.e. ICES Divisions IIIa, IV, VIId, and V-XIV; (ii) the Mediterranean, and (iii) other regions. The sampling strategies are identical in all three cases, so we focus on the NSCA for illustration purposes (Figure 1). In 2007, 3721 French vessels were fishing in that area, most of them small (50\% of the total fleet in numbers, $25 \%$ of the total engine power).

The division of the NSCA fleet into segments follows European Council regulation (EC, 2008), and is derived from both official data supplied by the French Ministry of Fisheries and a complementary survey of fishing activities carried out by Ifremer (Berthou et al., 2008). A fleet segment is defined by the vessel type and size, with small vessels (see above) being in a single size category. The heterogeneity of fishing revenues within a fleet segment is assessed by computing the coefficient of variation $(\mathrm{CV})$ across all vessels of a parameter of interest, $P$. To demonstrate the approach, $P$ is taken to be a proxy for fishing revenue, which is calculated by multiplying vessel capacity (length of vessel $\times$ crew size) by the intensity of fishing, i.e. the number of months in which the vessel was active for at least one day (Daurès et al., 2008). Details of the size of each NSCA fleet segment and the variation in the proxy fishing revenue within it (measured by the CVs) are presented in Table 1 . The heterogeneity in proxy fishing revenue is high, because the CVs vary between 0.18 and 0.75 across fleet segments (considering those with $>10$ vessels). The $C V$ is highest for small vessels using pots, and lowest for dredgers between 18 and $24 \mathrm{~m}$ long. More generally, the heterogeneity in proxy fishing revenue is higher for smaller vessels than for larger ones, with an overall $C V$ of 0.7 for the small-vessel segments.

The NSCA fleet thus comprises small vessels which are very heterogeneous, and larger vessels which are more homogeneous in terms of their fishing revenues.

\subsection{Two-stage sampling plan to obtain representative data}

The sampling design is probability sampling (STECF, 2009b), in which data are collected from a sample of vessels selected randomly. The plan is in two stages: (i) computation of the minimum sample size to be achieved for each fleet segment to meet the requirements for precision of sample-based estimates; and (ii) the allocation of these samples across MRDs to preclude geographic bias. The MRDs correspond to the vessels' administrative attachment, so vessels from the same MRD can actually fish in different areas.

In the DCF regulation, the precision $L$ (measured by the $C V$ of the estimator, or $C V e$ ) to be achieved for the fleet estimate of the parameter of interest $P$ is a CVe of 0.25 or better. Using standard sampling theory, the ideal sample-allocation plan, i.e. providing the best precision for the least cost, can be determined from Neyman allocation estimates for each fleet segment (Ardilly, 1994). The minimum sample size $n_{i}$ for segment $i$ is computed from the required precision $(L=0.25)$, the segment size $N_{i}$, and the population $C V$ of the parameter of interest $\left(C V_{i}\right)$ as

$$
n_{i}=N_{i} \frac{1}{1+\frac{N_{i} L^{2}}{4 C V_{i}^{2}}}
$$

The budget allocated for the programme, however, limits the total sample size to a maximum of 600 vessels (about $17 \%$ of the NSCA fleet), which allows a precision $L$ of the implemented sampling plan between 0.20 and 0.25 for all fleet segments to be achieved. 
The $n_{i}$ vessels to be sampled in fleet segment $i$ are allocated between MRDs to ensure the geographic representativeness of the collected data. For this, vessels are selected by systematic random sampling (Tillé, 2001) in five steps.

(i) All vessels of the fleet segment are ordered by maritime registration district (from north to south), and then by vessel length within each district.

(ii) $n_{i}$ statistical units (SU) of size $m_{i}\left(=N_{i} n_{i}\right)$ are identified from this ordered population; each SU defines a group of vessels which is considered statistically equivalent.

(iii) The first vessel of the sample is identified from a starting point chosen at random inside the first SU.

(iv) Subsequent vessels are thereafter selected at regular intervals of size $m_{i}$, so $n_{i}$ vessels are selected, one in each SU.

(v) If the owner does not wish to take part in the survey, that vessel is substituted by another that belongs to the same SU. For example, if $n_{i}=12$ and $N_{i}=100$ in step (ii), $m_{i}=8$ is calculated. If now in step (iii), the 7th vessel belonging to the first SU is selected by chance among vessels 1-8, then in step (iv), the next one to be selected is the $7+8=15$ th vessel, then the 23 rd vessel etc., moving down the list of vessels.

\subsection{Organizing data collection to reduce non-responses}

The EDCP is part of Ifremer's Fishery Information System (FIS; Leblond et al., 2008) and is included in the French national programme implemented under the DCF (Ministry of Fisheries, 2008). The collection of economic data is made through a network of Ifremer observers covering the French MRDs. The observers are also involved in other work, such as monitoring fishing-vessel activities and biologically sampling discards. The sampling plan is organized so that each observer has a portfolio of some 30 economic surveys to carry out in a specified maritime district. The observers are responsible for both arranging the interviews and entering the information collected into the database.

Interviews take place between February and June each year to collect economic data for the previous year, i.e. the year of surveyed activity. To ensure data consistency and completeness over the surveyed year, the interviewee needs to have full knowledge over the relevant period. That is why vessel owners are interviewed personally. In order to reduce the number of non-responses, three vessel categories are distinguished. The first, referred to as the panel population, are vessels that were successfully interviewed the year before. A panel vessel cannot be interviewed for more than four consecutive years. The second category contains the non-interviewable vessels, those that cannot be interviewed either because they were sold during the previous year (so that data are incomplete over the year of activity), or they were approached the year before and refused to join the panel. The third category is the structural population, which includes all other fishing vessels. The panel and structural subpopulations are sampled independently as described above, and the global sample is the combination of the two. The number of panel vessels approached is equal to the minimum between the number of panel vessels $N_{i p}$ in segment $i$ and $n_{i p M}=0.7 n_{i}$. If $N_{i p}<n_{i p M}$, then all panel vessels are approached. Subsequently, the number of structural vessels approached, $n_{i s}$, is $n_{i}-n_{i p}$. For example, if $n_{i}=10, N_{i}=40$, and $N_{i p}=12$, then $n_{i p}=\min (12,10 \times 0.7)=7$. The global sample will be a combination of seven panel vessels and three structural vessels, independently identified as described above.

The first economic questionnaire survey was carried out in 2001, in consultation and collaboration with economists from the University of Western Brittany (see Boncoeur, 1999), and has continued with few changes over the years. The questions are based on a monetary approach that also includes social indicators. The questionnaire consists of nine main sections in logical order; vessel owners are surveyed on their fishing activities, their related earnings and costs, and more specifically on the characteristics of their fishing vessel. The latter includes the type of hull, engine, fishing gear, electronic equipment, and the related 
costs. Technical documents (in French) describing the methodology, from sampling optimization to the questionnaire, and the software used to record the information collected, are available on the Ifremer website http://www.ifremer.fr/sih/.

Data collected from the economic survey are validated vessel by vessel and variable by variable in several steps, including tests of quality, consistency, and continuity between variables. All economic variables are collected in accord with the definitions in Appendix VI of EC (2008).

\section{Results of the EDCP}

As it is impractical to present all results across the 34 fleet segments, we focus here on five chosen to represent the diversity of the NSCA fleet in terms of activity and vessel length. Three are small-vessel segments, dredgers (SSDredgers), drift and/or fixed netters (SSNetters), and vessels using pots and/or traps (SSPots). The other two are demersal trawlers and/or seiners 10-12 m long (referred to as MediumDemersalTrawlers, or MDTrawlers), and 12-18 m long (referred to as LargeDemersalTrawlers, or LDTrawlers).

From 2000 to 2008, the NSCA fleet decreased by 18\%, from 4200 to 3500 vessels (Figure 2a). The small-vessel fleet declined less, by some $13 \%$ (Figure $2 \mathrm{~b}$ ). The NSCA sample varied from 425 vessels in 2008, the smallest sample, to 580 vessels in 2002, the largest sample (Figure 2a). The sample rate of the NSCA fleet showed no trend during the period, however, the budget restriction (600 vessels, or $17 \%$ of the total fleet) never being realized; the sample rates achieved were between 13 and 15\% (Figure 2a). Sampling rates of small vessels and the total fleet were similar (Figure $2 \mathrm{a}$ and $2 \mathrm{~b}$ ).

\subsection{Reliability of the sample}

The total sample size in 2008 was 533 vessels, i.e. 14.4\% of the fleet (Table 1). The largest sample size was that for small vessels using hooks (59 vessels, sampling rate 19\%). The sampling-rate range for all segments with $>10$ vessels was $8-30 \%$. The range of precision for the proxy fishing revenue for small vessels was $2-12 \%$, well within the DCF requirement. However, the precision was $>30 \%$ for two small fleet segments: vessels using hooks from 18 to $24 \mathrm{~m}$ long, and drift and fixed netters from 24 to $40 \mathrm{~m}$ long. Three other fleet segments had a precision between 25 and 30\%, again not in accord with the regulation.

As economic assessments are based on samples and not a census, it is important to look for any bias in the sampling design (STECF, 2009b). We examined sample representivity using Welch's $t$-test, an adaptation of the Student's $t$-test intended for use with two samples with possibly unequal variance. The Welch's $t$-test indicates whether the mean characteristic of the sample is the same as the population mean. For it to be applicable, the sample has to be either normally distributed or $>30$ vessels (Tufféry, 2010). This test was performed for the five fleet segments of the NSCA fleet for the variables vessel length, vessel power, and vessel age. The null hypothesis that the means of two groups (population/sample) were equal at a risk of $5 \%$ was tested, and the results demonstrated that sample and population means were not significantly different for any of the five fleet segments selected and for all vessel characteristics tested (results not shown).

The spatial distribution across MRDs of the sample collected for the five fleet segments analysed here was close to that of the population, though with small differences (Figure 3). 


\subsection{Substitute vessels and the number of non-responses}

During the EDCP in 2008 and based on 2007 data, 938 fishers were contacted, resulting in 533 interviews. In all, 405 fishers did not wish to participate, and another 330 were substituted by the procedure explained above. No substitution was possible for the remaining 75 cases. Ultimately, therefore, there were 75 non-responses, $13 \%$ of the successful interviews. The panel sample consisted of 251 vessels, around half the total. Nine fishers in the panel population, having been interviewed the year before and who had agreed to be on the panel then, declined to be interviewed again in 2008.

\subsection{Economic performance of selected NSCA fleets}

Here we show how the EDCP sample information improves estimation of some economic indicators. It is not, however, a complete economic assessment of the NSCA fleet, because that has already been reported in STECF (2009a). The comparison of gross revenue obtained from the EDCP data and with the official statistics (Ofimer, 2008) for the five fleet segments selected showed that the relative percentage difference between the two was negligible for LDTrawlers, and 15\% for MDTrawlers, but much larger for the segments with small vessels (30-46\%; Table 2).

We evaluated the economic performance for the period 2001-2009 using the following four indicators: gross revenue, fuel cost, operational costs (i.e. the sum of all costs other than fuel and crew related to fishing effort), and employment in terms of Full Time Equivalent (FTE). The latter is calculated as the average monthly crew size in a given year. Apart from the gross revenue presented above, the other parameters are not available from official data sources. Table 3 shows estimates of these indicators in 2007 as averages per vessel for the five fleet segments. The gross revenue ranged from $€ 65068$ for SSDredgers to $€ 454356$ for LDTrawlers. Fuel costs spanned the range $€ 4270$ for SSNetters to $€ 99535$ for LDTrawlers. Crew size varied between 1.5 FTE for SSNetters to 3.6 FTE for LDTrawlers.

To examine productivity, two indicators of effort (days at sea, and hours of engine running), and one capacity indicator, the average engine power per vessel, were considered. They provide estimates of four productivity ratios (R1-R4), listed in Table 3. The segments with small vessels had lower revenue productivity than the others. Revenue productivity in terms of gross revenue per crew size times days at sea (R1) was similar between the three segments with small vessels. The SSDredgers had the lowest revenue productivity in relation to engine power (R2). Energy productivity was relatively low for the segments with small vessels (Table 3 ).

\section{Discussion and conclusions}

We have presented the sampling methodology designed by Ifremer for the French EDCP. It provides economic data representative of the entire French fleet in terms of gross fishing revenues, across all fleet segments (including small vessels) and MRDs. The sampling strategy used in the EDCP is probability sampling. Errors in survey design were evaluated in terms of bias and precision following the recommendations of STECF (2009b). The sampling plan is representative of the overall fleet. There was no bias in terms of vessel characteristics of the sample, but a precision of economic indicators greater than $25 \%$ for most fleet segments. These results meet the requirements of the EU Data Collection Framework regulation.

The low level of final non-responses $(13 \%)$ is the result of the data collection being based on a network of Ifremer observers who collect data for various purposes, of which economic 
analysis is just one. It also stems from the provision for substitute vessels in the sampling plan. Nevertheless, the variability in sample sizes through years was notable, and mainly attributable to changes in the non-response rate caused by factors outside Ifremer's control, such as fishery-management policy developments, that are difficult to address.

Comparison of the EDCP data (gross revenues) with official statistics revealed differences in landing values of small vessels of up to $46 \%$. Given the representativeness of the sampling, it can be assumed that the official statistics are underestimates for these vessels. This justifies using the EDCP to estimate the economic importance of small-vessel segments of the fleet better. This is explained by the fact that official data are derived mainly from the records of auctions, which are the only commercial outlet for large vessels, whereas small vessels have alternative outlets such as direct sale to customers.

The economic indicators revealed considerable differences among the five fleet segments selected, in particular between small and large vessels; the former have greater heterogeneity and lower productivity. This result underlines the importance of assessing the economic performances of small and large vessels separately. Sumaïla et al. (2008) reported that the energy ratio (R4) varies from one fishery to another, and can be as much as $60 \%$. The NSCA ratios agree well with these observations, with the maximum being $71 \%$ for the MDTrawlers. The energy ratio was less for small vessels, especially for SSPots, for which it was just $32 \%$.

The sample size achieved corresponds to $15 \%$ of the fishing fleet, i.e. $2 \%$ less than the sampling plan. The samples collected were often not sufficient to be useful for regional assessments, but the use of additional data sources such as accounting information is one way of increasing the sample size and, consequently, improving the precision of the economic indicators derived.

There is a great diversity of sampling approaches for collecting economic data in Europe, limiting the comparability and homogenization of data between Member States (STECF, 2009b). However, the effectiveness of different sampling schemes for economic data is currently being evaluated across Europe. Three types of data-collection scheme have been identified by the Joint Working Group on Economic Affairs (SGECA): (i) Type A is a census, with data collected from the entire population, (ii) Type B a probability-sample survey, in which data are collected from a random sample of the population (examples are the French EDCP described here, and a similar scheme in Italy; Italian Ministry of Agricultural and Forestry Policy, 2009), and (iii) Type C, a non-probability sample survey, in which data are collected from a sample of population members that is not selected randomly, e.g. Netherlands Directorate of Fisheries (2008).

Even for a given type of sample collection, strategies can be based on different optimization algorithms. We used a Neyman allocation across fleet segments based on the level of heterogeneity of revenues. The Italian scheme uses the Bethel methodology, a generalization of the Neyman allocation and based on the level of heterogeneity for a bundle of variables (Sabatella and Franquesa, 2004). The Bethel methodology allows costs to be minimized for a given level of precision for the bundle of variables selected. Future research in relation to the French EDCP needs to investigate the sample representativeness for variables other than revenue. This would allow more direct comparisons between the French and Italian data collection programmes.

We only studied landings made in NSCA MRDs and future research could include those made elsewhere. Our spatial analysis is restricted to the MRDs of the vessels, but a wider analysis has been made in the Bay of Biscay (Daurès et al., 2009), and other studies by fishing area are ongoing within Ifremer. 
The interest of this work lies not just in the results of the sampling strategies, but in how the methodology itself was developed; these strategies could be applied elsewhere.

\section{Acknowledgements}

We especially thank the fishers who agreed to participate in the EDCP. From Ifremer, we thank the team of Ifremer observers involved in the programme, E. Rostiaux, P, Raulin, J. Quinquis, D. Miossec, H. Barone, P. Raguenes, and G. Morandeau, Michèle Jézéquel for IT tool design and support, Mathilde Pitel for mapping the surveyed area, and S. Demanèche, E. Leblond, and P. Berthou for their contributions to the EDCP. We are also extremely grateful to V. Trenkel, the guest editor, to D. N. MacLennan, the journal editor, and to two anonymous reviewers for their helpful suggestions on the submitted version of this paper.

\section{References}

Ardilly, P. 1994. Les Techniques de Sondage. Technip, Paris. 393 pp.

Berthou, P., Guyader, O., Leblond, E., Demanèche, S., Daurès, F., Merrien, C., and Lespagnol, P. 2008. From fleet census to sampling schemes: an original collection of data on fishing activity for the assessment of the French fisheries. ICES Document CM 2008/K: 12. $17 \mathrm{pp}$.

Boncoeur, J., and Le Gallic, B. 1999. Enquête économique sur la pêche professionnelle française en Manche. CEDEM (UBO). Brest, France. 81 pp.

Chuenpagdee, R., Liguoriand, L., Palomares, L., and Pauly, D. 2006. Bottom-up, global estimates of small-scale fisheries catches. Fisheries Centre Research Reports, 14(8). 110 pp.

Daurès, F., Rochet, M-J., Van Iseghem, S., and Trenkel, V. M. 2009. Fishing fleet typology, economic dependence, and species landing profiles of the French fleets in the Bay of Biscay, 2000-2006. Aquatic Living Resources, 22: 535-547.

Daurès, F., Van Iseghem, S., Demaneche, S., Leblond, E., Brigaudeau, C., Guyader, O., and Berthou, P. 2008. Re-assessing the French small-scale coastal fisheries from fleet activity to economic performance. ICES Document CM 2008/K: 10. 16 pp.

EC. 2008. Commission decision adopting a multi-annual Community programme pursuant to Council Regulation (EC) No 199/2008. Official Journal of the European Union, Issn 17252555, I60, volume $51.52 \mathrm{pp}$.

FAO. 1995. Code of Conduct for responsible fisheries. Food and Agriculture Organization, Rome. $41 \mathrm{pp}$.

Garcia, S. M. 2005. Ecosystem approach to fisheries: a review of implementation guidelines. ICES Journal of Marine Science, 62: 311-318.

Italian Ministry of Agricultural and Forestry Policy. 2009. Italian National Programme under Council Regulation (EC) $N^{\circ} 199 / 2008$ and Commission Regulation (EC) $N^{\circ}$ 665/2008. Ministero delle Politiche Agricole e Forestali, Viale dell'Arte, Rome. 123 pp. Available at https://datacollection.jrc.ec.europa.eu.

Leblond, E., Daurès, F., Berthou, P., and Dintheer, C. 2008. The Fisheries Information System of Ifremer: a multidisciplinary monitoring network and an integrated approach for the assessment of French fisheries, including small-scale fisheries. ICES Document CM 2008/K: 11. 8 pp.

Le Pape, O., and Vigneau, J. 2001. The influence of vessel size and fishing strategy on the fishing effort for multispecies in north-western France. ICES Journal of Marine Science, 58: $1232-1242$. 
Macher, C., Guyader, O., Talidec, C., and Bertignac, M. 2008. A cost-benefit analysis of improving trawl selectivity in the case of discards: the Nephrops norvegicus fishery in the Bay of Biscay. Fisheries Research, 92: 76-89.

Mettling, B., Henaff, P., Mingasson, A., and Menanteau, J. P. 1995. Rapport d'audit sur la situation financière des navires de pêche artisanale et des organismes d'intervention. Rapport du ministère de l'agriculture et de la pêche. Paris, France. 31 pp. + Appendix.

Ministry of Fisheries. 2008. French National Program 2009-2010 under Council Regulation (EC) $N^{\circ} 199 / 2008$ and Commission Regulation (EC) $N^{\circ} 665 / 2008$. Ministère de l'agriculture et de la pêche, Direction des pêches maritimes et de l'aquaculture. 3 Place de Fontenoy, 75007 Paris. Available at https://datacollection.jrc.ec.europa.eu. 103 pp.

Netherlands Directorate of Fisheries. 2008. The Netherlands National Programme 20092010 - the drawing-up of the programme of the Data Collection Regulation. Netherlands Directorate of Fisheries, Bezuidenhoutseweg 73, Postbox 20401, 2500 Gravenhage. 79 pp. Available at https://datacollection.jrc.ec.europa.eu.

Ofimer, 2008. Key figures for the fisheries and aquaculture sector in France, 2008 edn. 36 pp. Available at http://www.ofimer.fr/Pages/Ofimer/Publications.html.

Pascoe, S. 2006. Economics, fisheries, and the marine environment. ICES Journal of Marine Science, 63: 1-3.

Sabatella, E., and Franquesa, R. 2004. Manual of fisheries sampling surveys: methodologies for estimation of socio-economic indicators in the Mediterranean Sea. FAO Studies and Reviews, 73. 48 pp.

Sumaila, U.R., Teh, L., Watson, R., Tyedmers, P., and Pauly, D. 2008. Fuel price increase, subsidies, overcapacity, and resource sustainability. ICES Journal of Marine Science, 65: 832-840.

STECF. 2009a. Scientific, Technical and Economic Committee for Fisheries (STECF). Report of the Working Group on the Preparation of Annual Economic Report (SGECA 0901). Publications Office of the European Union, Luxembourg. 312 pp. ISBN 978-92-7914049-5.

STECF. 2009b. Scientific, Technical and Economic Committee for Fisheries (STECF). Report of the Working Group on the quality aspects of the collection of economic data methods of calculation of the indicators and sampling strategies (SGECA 09-03). Publications Office of the European Union, Luxembourg. 62pp. ISBN 978-92-79-15356-3.

Tillé, Y. 2001. Théorie des sondages. Dunod, Paris. 284 pp.

Tufféry, S. 2010. Data Mining et statistique décisionnelle. Technip, Paris. 700 pp. 

Tables

Table 1. Characteristics of the French fleet operating in the North Sea Channel Atlantic region in 2007 by length category, and details of the sampling plan.

\begin{tabular}{|c|c|c|c|c|c|c|c|c|c|c|c|c|c|c|c|c|c|c|c|c|c|c|c|c|c|c|c|c|c|c|}
\hline \multirow[b]{2}{*}{ Vessel } & \multicolumn{6}{|c|}{ Number of vessels } & \multicolumn{6}{|c|}{ Index of variability $C V(\%)$} & \multicolumn{6}{|c|}{ Sample size } & \multicolumn{6}{|c|}{ Sample rate (\%) } & \multicolumn{6}{|c|}{$\begin{array}{c}\text { Sample } C V \text { of gross revenue (Cve - } \\
\%)\end{array}$} \\
\hline & $\begin{array}{c}<\mathbf{1 0} \\
\mathbf{m}\end{array}$ & $\begin{array}{c}10- \\
12 \mathrm{~m}\end{array}$ & $\begin{array}{l}12- \\
18 \\
\mathrm{~m}\end{array}$ & $\begin{array}{l}18- \\
24 \\
\text { m }\end{array}$ & $\begin{array}{l}24- \\
40 \\
\text { m }\end{array}$ & $\begin{array}{c}\geq \mathbf{4 0} \\
\mathrm{m}\end{array}$ & $\begin{array}{l}<10 \\
\mathbf{m}\end{array}$ & $\begin{array}{c}\text { 10- } 12 \\
\text { m }\end{array}$ & $\begin{array}{l}12- \\
18 \\
\mathrm{~m}\end{array}$ & $\begin{array}{l}18- \\
24 \\
\mathrm{~m}\end{array}$ & $\begin{array}{l}24- \\
40 \\
\text { m }\end{array}$ & $\begin{array}{l}\geq \mathbf{4 0} \\
\mathrm{m}\end{array}$ & $\begin{array}{l}<\mathbf{1 0} \\
\mathbf{m}\end{array}$ & $\begin{array}{c}10- \\
12 \mathrm{~m}\end{array}$ & $\begin{array}{l}12- \\
18 \\
\mathrm{~m}\end{array}$ & $\begin{array}{l}18- \\
24 \\
\text { m }\end{array}$ & $\begin{array}{l}24- \\
40 \\
\text { m }\end{array}$ & $\geq 40 \mathrm{~m}$ & $\begin{array}{l}<\mathbf{1 0} \\
\mathbf{m}\end{array}$ & $\begin{array}{c}10- \\
12 \mathrm{~m}\end{array}$ & $\begin{array}{l}12- \\
18 \\
\mathrm{~m}\end{array}$ & $\begin{array}{l}18- \\
24 \\
\mathrm{~m}\end{array}$ & $\begin{array}{l}24- \\
40 \\
\text { m }\end{array}$ & $\geq 40 \mathrm{~m}$ & $\begin{array}{c}<\mathbf{1} \\
\mathbf{0} \\
\mathbf{m}\end{array}$ & $\begin{array}{c}\text { 10- } 12 \\
\text { m }\end{array}$ & $\begin{array}{l}12- \\
18 \\
\text { m }\end{array}$ & $\begin{array}{l}18- \\
24 \\
\text { m }\end{array}$ & $\begin{array}{l}\mathbf{2 4 -} \\
\mathbf{4 0} \\
\mathrm{m}\end{array}$ & $\begin{array}{l}>=4 \\
0 \mathrm{~m}\end{array}$ \\
\hline Beam trawlers & & & 6 & & 2 & & 0 & 0 & 17 & 0 & 13 & 0 & & & 2 & & & & & & 33 & & & & & 4 & & & & \\
\hline Demersal trawlers and/or demersal seiners & 118 & 193 & 219 & 233 & 84 & 13 & 44 & 35 & 34 & 30 & 44 & 30 & 10 & 32 & 21 & 25 & 5 & & 8 & 17 & 10 & 11 & 6 & & 7 & 1 & 2 & 1 & 15 & \\
\hline Pelagic trawlers & & 4 & 20 & 40 & 3 & 4 & 0 & 26 & 45 & 28 & 19 & 48 & & 1 & 4 & 4 & & & & 25 & 20 & 10 & & & & 20 & 16 & 7 & & \\
\hline Pelagic seiners & & 2 & 25 & 2 & 1 & 22 & 0 & 24 & 30 & 54 & 0 & 16 & & 1 & 5 & & & & & 50 & 20 & & & & & 12 & 6 & & & \\
\hline Dredgers & 82 & 77 & 97 & 11 & & & 51 & 42 & 34 & 18 & 0 & 0 & 15 & 13 & 10 & 2 & & & 18 & 17 & 10 & 18 & & & 6 & 5 & 4 & 5 & & \\
\hline Vessel using other active gears & 251 & 8 & & & & & 69 & 32 & 0 & 0 & 0 & 0 & 35 & & & & & & 14 & & & & & & 5 & & & & & \\
\hline $\begin{array}{l}\text { Vessels using polyvalent "active" gears } \\
\text { only }\end{array}$ & 31 & 54 & 50 & 3 & & & 57 & 44 & 28 & 92 & 0 & 0 & 8 & 12 & 11 & & & & 26 & 22 & 22 & & & & 12 & 5 & 2 & & & \\
\hline Vessels using hooks & 303 & 45 & 8 & 8 & 10 & & 59 & 36 & 49 & 65 & 29 & 0 & 59 & 14 & 3 & 3 & 1 & & 19 & 31 & 38 & 38 & 10 & & 2 & 3 & 20 & 35 & 30 & \\
\hline Drift and/or fixed netters & 335 & 196 & 94 & 40 & 19 & 1 & 69 & 36 & 32 & 44 & 31 & 0 & 42 & 19 & 16 & 6 & 1 & & 13 & 10 & 17 & 15 & 5 & & 4 & 2 & 2 & 11 & 36 & \\
\hline Vessels using pots and/or traps & 308 & 65 & 7 & 11 & & & 75 & 34 & 44 & 20 & 0 & 0 & 42 & 17 & 2 & 7 & & & 14 & 26 & 29 & 64 & & & 5 & 2 & 28 & 1 & & \\
\hline Vessels using other passive gears & 106 & 6 & & & & & 60 & 31 & 0 & 0 & 0 & 0 & 29 & & & & & & 27 & & & & & & 4 & & & & & \\
\hline $\begin{array}{l}\text { Vessels using polyvalent "passive" gears } \\
\text { only }\end{array}$ & 97 & 10 & 3 & & & & 66 & 41 & 14 & 0 & 0 & 0 & 22 & 2 & & & & & 23 & 20 & & & & & 6 & 27 & & & & \\
\hline Vessels using active and passive gears & 93 & 92 & 13 & 1 & & & 51 & 35 & 32 & 0 & 0 & 0 & 15 & 14 & 3 & & & & 16 & 15 & 23 & & & & 6 & 3 & 11 & & & \\
\hline Inactive vessels & 152 & 21 & 8 & 12 & 2 & & 0 & 0 & 0 & 0 & 0 & 0 & & & & & & & & & & & & & & & & & & \\
\hline Total by number & 1876 & 773 & 550 & 361 & 121 & 40 & 70 & 41 & 36 & 36 & 54 & 66 & 277 & 125 & 77 & 47 & 7 & 0 & 15 & 16 & 14 & 39 & 17 & 0 & & & & & & \\
\hline
\end{tabular}

The index of variability is the coefficient of variation, $C V$ (standard deviation divided by mean), of the proxy fishing revenue, estimated as the length of the vessel $\times$ crew size $\times$ fishing intensity (months) on the whole population. The sample $C V$ of the gross revenue $(C V e)$ is based on 2007 data. 
Table 2. Comparison of gross-revenue, sample-based estimates and official landings statistics (Ofimer, 2008) by fleet segment for 2007.

\begin{tabular}{|c|c|c|c|c|c|}
\hline Parameter & SSDredgers & SSNetters & SSPots & MDTrawlers & LDTrawlers \\
\hline Number of vessels in fleet & 82 & 335 & 308 & 193 & 219 \\
\hline Number of vessels in sample & 15 & 42 & 42 & 31 & 21 \\
\hline \multicolumn{6}{|c|}{ Economic indicator, whole fleet $(€)$} \\
\hline Official landings & 3731889 & 17389799 & 17684290 & 39449883 & 100519643 \\
\hline EDCP gross revenue & 5335563 & 25510528 & 33010802 & 46354796 & 99504055 \\
\hline Relative difference & $30 \%$ & $32 \%$ & $46 \%$ & $15 \%$ & $-1 \%$ \\
\hline
\end{tabular}

The relative percentage difference between the gross revenue derived from raised EDCP samples (ledcp) and official landings (lo) is calculated as 100(ledcp - lo)/ledcp. Small-vessel segments $(<10$ $\mathrm{m}$ ): dredgers (SSDredgers), drift and/or fixed netters (SSNetters), and vessels using pots and/or traps (SSPots); medium-sized demersal trawlers and/or seiners (10-12 m; MDTrawlers); large demersal trawlers (12-18 m; LDTrawlers).

Table 3. Indicators of economic performance of selected vessels of the French North Sea Channel Atlantic fleet for 2007.

\begin{tabular}{|c|c|c|c|c|c|}
\hline Parameter & SSDredgers & SSNetters & SSPots & MDTrawlers & LDTrawlers \\
\hline \multicolumn{6}{|c|}{ Economic indicator (average per vessel, €) } \\
\hline EDCP gross revenue G & 65068 & 76151 & 107178 & 240180 & 454356 \\
\hline Fuel cost $\mathrm{F}$ & 4541 & 4270 & 6687 & 41616 & 99535 \\
\hline Variable costs V & 7762 & 7984 & 20581 & 58143 & 143204 \\
\hline Crew size (ETP) S & 2.3 & 1.5 & 2.0 & 2.6 & 3.6 \\
\hline Effort (days at sea) E1 & 95 & 177 & 180 & 197 & 200 \\
\hline Effort (engine hours) E2 & 799 & 1325 & 1253 & 2863 & 3989 \\
\hline \multicolumn{6}{|l|}{ Fishing capacity indicator } \\
\hline Power (mean kW per vessel) W & 105 & 76 & 93 & 150 & 278 \\
\hline Number of vessels & 82 & 335 & 308 & 193 & 219 \\
\hline \multicolumn{6}{|l|}{ Ratio } \\
\hline Revenue productivity (G/S E1) R1 & 298 & 293 & 296 & 465 & 638 \\
\hline Revenue productivity (G/W) R2 & 622 & 1003 & 1149 & 1604 & 1632 \\
\hline Energy productivity (F/E2) R3 & 6 & 3 & 5 & 15 & 25 \\
\hline Energy productivity (F/V) R4 & 0.585 & 0.535 & 0.325 & 0.716 & 0.695 \\
\hline
\end{tabular}

Small-vessel segments ( $<10 \mathrm{~m}$ ): dredgers (SSDredgers), drift and/or fixed netters (SSNetters), and vessels using pots and/or traps (SSPots); medium-sized demersal trawlers and/or seiners (10-12 m; MDTrawlers); large demersal trawlers (12-18 m; LDTrawlers). 


\section{Figures}

Figure 1. Maritime registration district (MRD) of the French North Sea Channel Atlantic fleet, and the number of fishing vessels registered by size category $(<10 \mathrm{~m}$ and $\geq 10 \mathrm{~m})$ in 2008 .

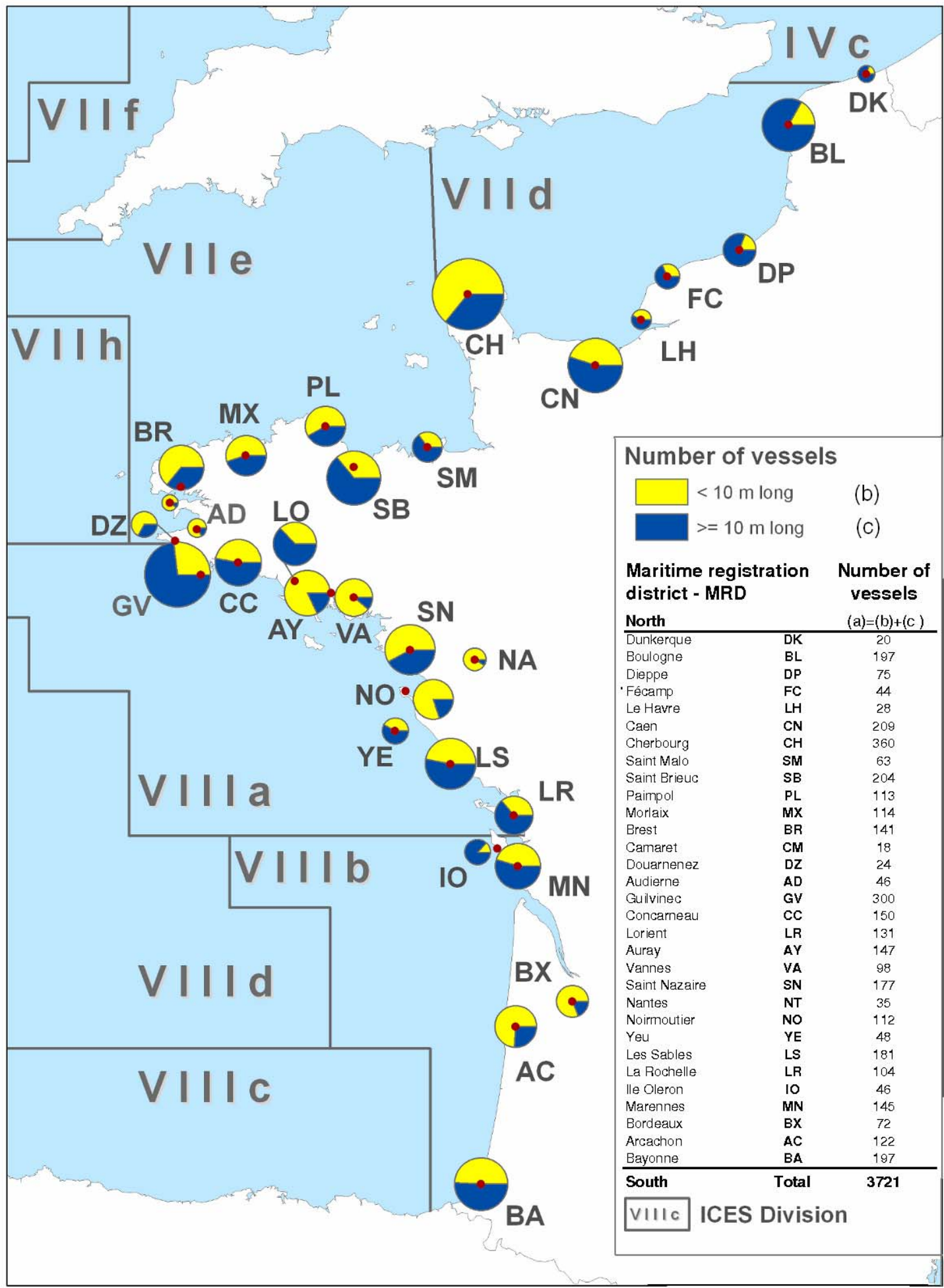


Figure 2. Changes in the number of vessels in the French fleet operating in the North Sea Channel Atlantic region and the number of samples by year between 2000 and 2008. (a) All vessels, (b) small vessels $(<10 \mathrm{~m})$.
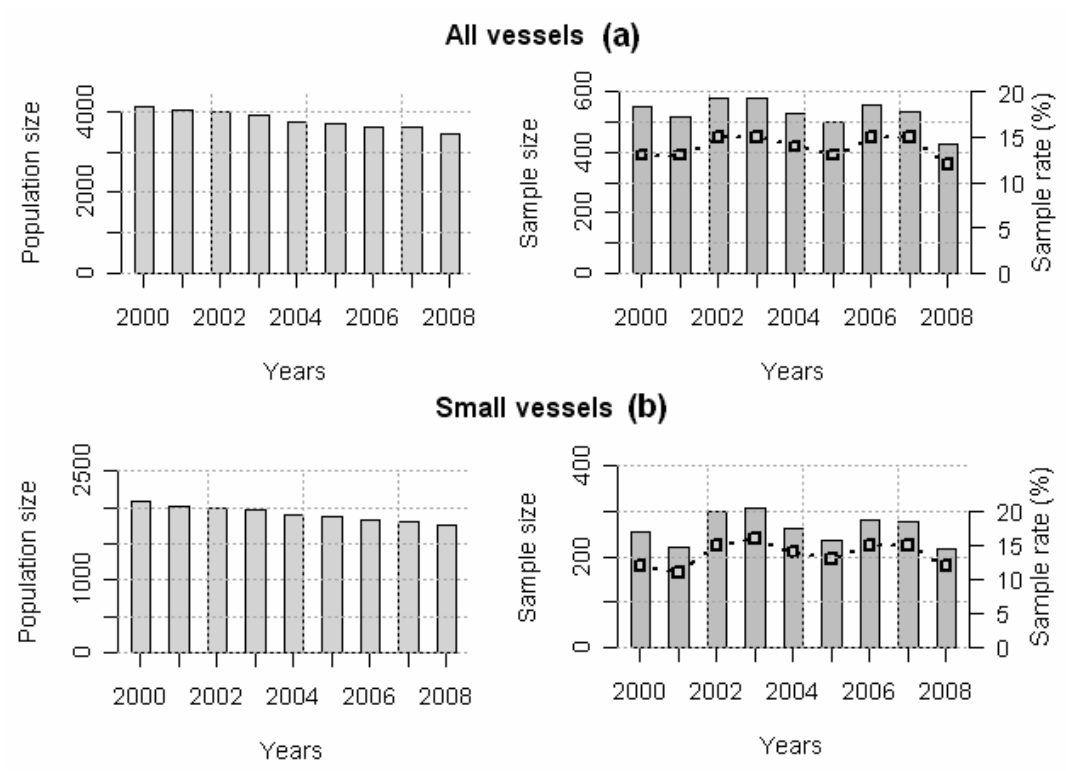
Figure 3. Spatial distribution as the percentage of vessels by maritime district for five fleet segments for the population and the sample in 2007. Small-vessel segments $(<10 \mathrm{~m})$ : dredgers (SSDredgers), drift and/or fixed netters (SSNetters), and vessels using pots and/or traps (SSPots); medium-sized demersal trawlers and/or seiners (10-12 m; MDTrawlers); large demersal trawlers (12-18 m; LDTrawlers).

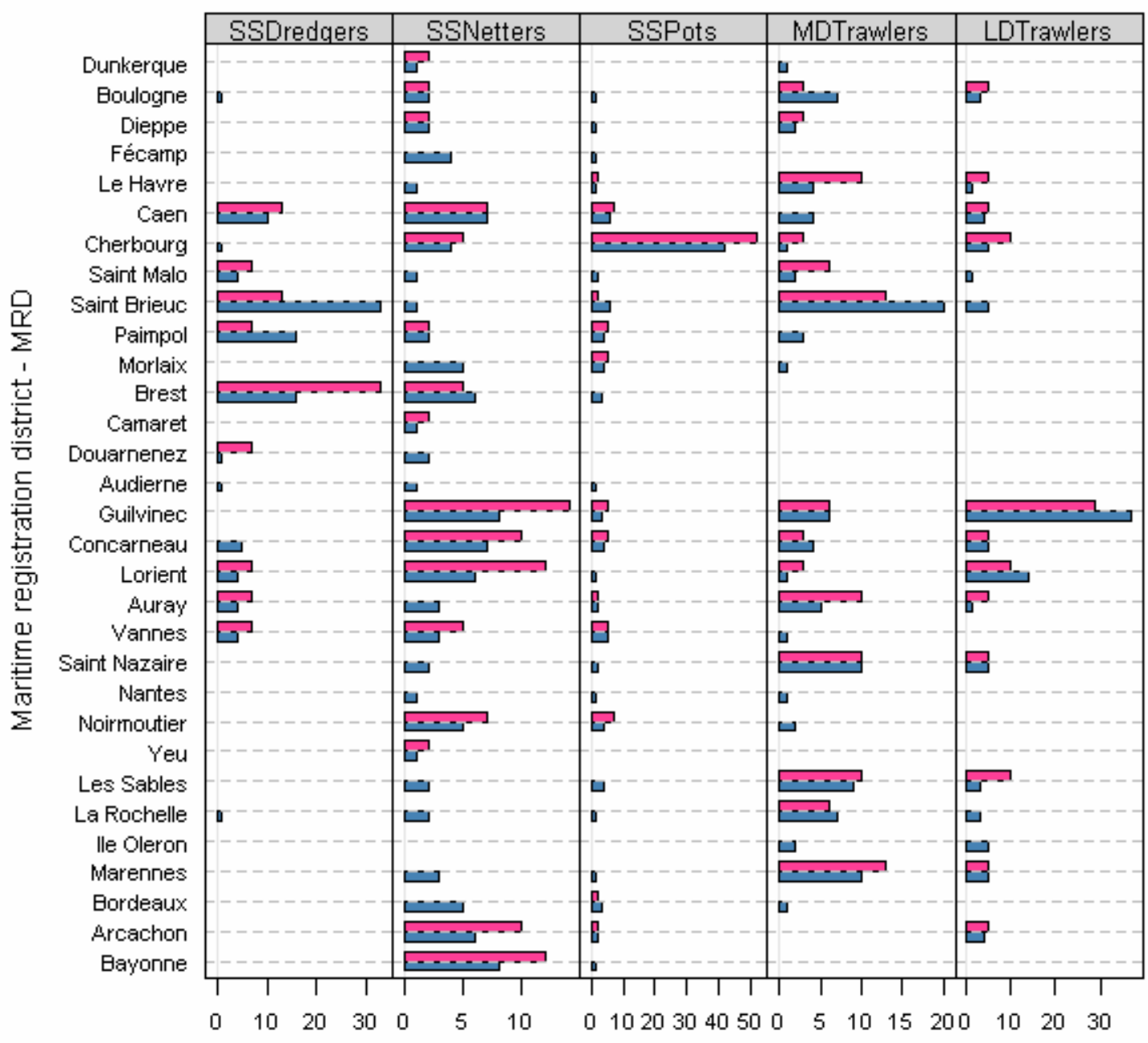

Number of vessels (in percentage of the total number of vessels of the segment) population sample 